\title{
Penerapan Manajemen Pembelajaran Terhadap Hasil Belajar Peserta Kursus Pada Lembaga Kursus Mengemudi “PRIVATE” Di Kabupaten Jember
}

\author{
Alvin Septian, Niswatul Imsiyah, Lutfi Ariefianto \\ Program Studi Pendidikan Luar Sekolah, Jurusan Ilmu Pendidikan, Fakultas Keguruan dan Ilmu Pendidikan \\ Universitas Jember. Jl. Kalimantan No. 37, TegalBoto, Jember 62811, Indonesia \\ Email: niswatul@unej.ac.id
}

\begin{abstract}
Abstrak
Ketidakberhasilan suatu lembaga kursus mengemudi terjadi karena adanya kesalahan dalam pengelolaan dalam penerapan yang di lakukan oleh instruktur itu sendiri dan bisa jadi lulusan dalam proses pembelajaran akan tidak efektif.. Jenis penelitian deskriptif dengan pendekatan kualitatif. Informan penelitian ditentukan menggunakan teknik Snowball Sampling. Pengumpulan data dilakukan dengan wawancara, observasi dan dokumentasi. Supaya kepercayaan terhadap data menjadi tinggi digunakan beberapa teknik keabsahan data yakni perpanjangan keikutsertaan, ketekunan pengamatan, dan triangulasi.. Analisis data menggunakan analisis model Miles dan Huberman yakni Pengumpulan data, reduksi data, penyajian data, dan verifikasi data. Hasil penelitian menunjukkan LKP "PRIVATE" dalam perencanaan pembelajaran meliputi rancangan pelaksanaan pembelajaran, Dalam pelaksanaannya terhadap hasil belajar instruktur melaksanakan rencana kegiatan pembelajaran yang telah dibuat di awal dalam perangkat pembelajaran. Selanjutnya dalam Penilaian atau evaluasi yang dilakukan, menggunakan prosedur dan instrumen untuk mengetahui pencapaian kompetensi dasar dan disesuaikan dengan yang ada pada kurikulum. dan hasil belajar setelah peserta mengikuti kursus peserta dapat mengembangkan kemampuan kognitif, afektif dan psikomotoriknya.
\end{abstract}

Kata Kunci: Manajemen Pembelajaran, Hasil Belajar, Kursus Mengemudi.

\section{Application of Learning Management to Learning Outcomes of Course ParticipantsAt the "PRIVATE" Driving Course Institute Jember Regency}

\begin{abstract}
The failure of a driving course institution occurs due to management errors in the implementation carried out by the instructor itself and may be graduates in the learning process will be ineffective. This type of research is descriptive with a qualitative approach. The research informants were determined using the Snowball Sampling technique. Data collection is done by interviews, observation and documentation. In order for trust in data to be high, several techniques of data validity are used, namely the extension of participation, persistence of observation, and triangulation. Data analysis using Miles and Huberman model analysis, namely data collection, data reduction, data presentation, and data verification. The results of the study show that "PRIVATE" LKP in planning le arning includes the design of the implementation of learning, in its implementation of the learning outcomes the instructor implements a plan of learning activities that have been made early in the learning device. Furthermore, in the assessment or evaluation carried out, use procedures and instruments to determine the achievement of basic competencies and adapted to those in the curriculum. and learning outcomes after participants take the course participants can develop their cognitive, affective and psychomotor abilities.
\end{abstract}

Keywords: Learning Management, Learning Outcomes, Driving Course. 


\section{Learning Community: Jurnal Pendidikan Luar Sekolah, 3 (2), September 2019 - 32 Alvin Septian}

\section{PENDAHULUAN}

Lembaga kursus merupakan satuan Pendidikan Nonformal. Pendidikan di bagi menjadi 3 jalur yaitu Pendidikan (Formal, Non Formal Dan Informal) yang mempunyai fungsi yang strategis Dalam penjelasan pasal 26 ayat 5 Undang-undang Nomor 20 Tahun 2003, dijelaskan bahwa Kursus Dan Pelatihan adalah bentuk Pendidikan berkelanjutan untuk mengembangkan kemampuan peserta kursus dengan penekanan pada penguasaan keterampilan, standar kompetensi, pengembangan sikap kewirausahaan serta pengembangan kepribadian professional.

Tujuan kursus sebagai salah satu bentuk penyelenggaraan pendidikan pada jalur non formal yang memberikan kesempatan bagi masyarakat yang ingin mengembangkan pendidikan keterampilannya yang tidak dapat ditempuh melalui jalur pendidikan formal. Kursus dan pelatihan mempunyai tujuan yang sama, yaitu untuk meningkatkan pengetahuan, sikap dan keterampilan peserta didik yang sesuai dengan kebutuhannya, sehingga peserta didik memiliki bekal untuk mendapatkan peluang bekerja di perusahaan, atau peluang untuk membuka usaha sendiri dalam rangka meningkatkan kualitas hidupnya.

Keberhasilan suatu program tentunya membutuhkan manajemen pembelajaran yang baik, agar menghasilkan output atau lulusan yang baik pula, menurut Sahertian (2000: 134), mengelola pembelajaran meliputi: "merencanakan program belajar mengajar, melaksanakan proses belajar mengajar, menilai proses dan hasil, serta mengembangkan manajemen kelas" 6 . Perencanaan merupakan hal yang paling mendasar dalam manajemen, yang meliputi proses penyusunan materi pelajaran, silabus, RPP. Selanjutnya adalah pelaksanaan, pelaksanaan/Actuating itu sangatlah penting untuk pencapaian tujuan karena berfungsi untuk memberikan pengarahan, bimbingan atau biasa di sebut juga aktualisasi penerapan fungsi manajemen perencanaan terkait visi-misi yang telah di tetapkan. Selanjutanya adalah Evaluasi, evaluasi sangat berpengaruh terhadap keberhasilan suatu program. Evaluasi adalah suatu proses yang sistematis dan berkelanjutan untuk menentukan kualitas (nilai dan arti) daripada sesuatu berdasarkan pertimbangan dan kriteria tertentu untuk membuat suatu keputusan. Evaluasi merupakan sarana penting dalam meraih tujuan belajar mengajar. Tutor sebagai pengelola kegiatan belajar mengajar dapat mengetahui kemampuan siswanya, ketetapan metode mengajar yang digunakan dan keberhasilan siswa dalam meraih tujuan pembelajaran yang telah ditetapkan melalui kegiatan evaluasi

Ketidakberhasilan suatu lembaga kursus mengemudi terjadi karena adanya kesalahan dalam pengelolaan/ manajemen penerapan yang di lakukan oleh instruktur itu sendiri dan bisa jadi output/hasil belajar dalam proses pembelajaran akan terhambat/tidak efektif. Menurut Sudjana (2009: 3) "mendefinisikan hasil belajar siswa padahakikatnya adalah perubahan tingkah laku sebagai hasil belajar dalam pengertian yang lebih luas mencakup bidang kognitif, afektif dan psikomotor".

Adapun parameter deskripsi capaian pembelajaran khusus bidang profesi pengemudi profesional kendaraan pribadi sesuai KKNI level 2, Menurut Standart Kompetensi Lulusan (SKL) Direktorat Pembinaan Kursus dan Pelatihan Direktorat Jenderal Pendidikan Anak Usia Dini, Nonformal Dan Informal Kementerian Pendidikan Dan Kebudayaan (2014) Berkenaan dengan hasil belajar intelektual ranah kognitif Pengetahuan hafalan (Knowledge) ialah tingkat kemampuan untuk mengenal atau mengetahui adanya respon, fakta, atau istilah-istilah tanpa harus mengerti, atau dapat menilai dan menggunakannya. Menguasai pengetahuan procedural, faktual, prinsip-prinsip tentang kendaraan dan teknik berkendaraan ringan yang meliputi a. Pengetahuan factual tentang spesifikasi, instrument dan indikatorindikator pada kendaraan b. Pengetahuan tentang prinsip dan teknik pengoperasian kendaraan bermotor yang ekonomis dan ramah lingkungan. Berkenaan dengan hasil belajar intelektual ranah afektif (sikap) yaitu a. Mentaati Undang-undang Lalu-lintas dan Angkutan Jalan yang berlaku b. Memiliki rasa empati yang kuat terhadap keamanan, keselamatan, ketertiban dan kelancaran 


\section{Learning Community: Jurnal Pendidikan Luar Sekolah, 3 (2), September 2019 - 33 Alvin Septian}

(kamseltibcar) lalulintas baik bagi dirinya sendiri, pengguna jalan lain maupun masyarakat dilingkungan sekitarnya. Berkenaan dengan hasil belajar intelektual ranah psikomotorik (ketrampilan) yaitu a. Mengemudikan dan mengendalikan kendaraan bermotor secara efisien dan ramah lingkungan dengan memperhatikan keselamatan, kesehatan kerja serta keamanan dalam berkendaraan b. Mempersiapkan pengoperasian kendaraan bermotor dan mengidentifikasi kelayakan kendaraan.

\section{METODE}

Penelitian ini dilakukan dengan menggunakan jenis penelitian deskriptif dengan pendekatan kualitatif, penelitian deskripsi yaitu penelitian yang berusaha untuk mendeskripsikan sesuatu kondisi secara objektif berdasarkan data-data yang ada $^{5}$. Metode penentuan tempat menggunakan purposive area yang berlokasikan di LKP "PRIVATE" Jember. Penentuan informan penelitian menggunakan snowball sampling adapun yang menjadi informan kunci dalam kursus mengemudi ini adalah instruktur dan peserta kursus mengemudi, sedangkan informan pendukung yakni. Staff admin LKP PRIVATE Jember. Penelitian ini dimulai dengan observasi awal yang dilakukan sejak bulan Agustus 2017 hingga bulan Mei 2017, dengan rincian yakni, bulan Agustus hingga November 2017 peneliti melakukan observasi situasi social kemudian menyusun rumusan masalah yang digunakan dalam penelitian, bulan Desember 2017 sampai Januari 2018 persiapan penelitian. Bulan Februari hingga April 2018 peneliti melakukan pengumpulan data dan bulan Mei 2018 peneliti menyusun laporan hasil pengumpulan data. Peneliti mengumpulkan data melalui wawancara, observasi dan dokumentasi. Hasil penelitian ditulis dalam bentuk narasi dan kutipan langsung. Uji keabsahan data penelitian ini menggunakan perpanjangan pengamatan, peningkatan ketekunan, dan triangulasi teknik serta triangulasi sumber. Analisis dilakukan dengan pengumpulan data, reduksi data, penyajian data dan verifikasi data atau penarikan kesimpulan.

\section{HASIL DAN PEMBAHASAN}

Penyusunan perangkat pembelajaran memang sudah di tentukan pada kurikulum yang ada di pusat yaitu di kota malang, dan instruktur hanya melaksanakan mengikuti yang sudah di tetapkan. Dalam proses pembelajaran peserta di beri wawasan atau ilmu mengenal tools yang ada di kendaraan tersebut karena dalam mengemudi tidak harus hanya bisa mengoprasikan kendaraan saja akan tetapi perlu mengetahui fungsi, letak komponen pada mobil tersebut setelah penyampaian materi mengenai tools kendaraan peserta dapat mengetahui letak dan fungsi komponen yang ada pada kendaraan tersebut. Dalam berkendara semua orang wajib Mentaati Undang-undang Lalu-lintas dan Angkutan Jalan yang berlaku selain demi keselamatan diri sendiri juga orang lain demikian juga dalam mengikuti kursus mengemudi instruktur selalu memberikan himbauan-himbauan menerapkan taat berlalu lintas semisal dalam mendekati lampu merah dalam jarak kurang lebih 25 meter instruktur selalu mengingatkan agar selalu mengurangi laju kendaraan harus sabar dan taat dalam berlalu lintas. Dalam berkendara peserta selalu di beri materi Mengemudikan dan mengendalikan kendaraan bermotor secara efisien dan ramah lingkungan dengan memperhatikan keselamatan, kesehatan kerja serta keamanan dalam berkendara, pemakaian sabuk pengaman merupakan contoh dalam memperhatikan keselamatan berkendara, posisi tangan memegang stir kemudi juga merupakan Mengemudikan dan mengendalikan kendaraan bermotor secara efisien

Pelaksanaan yang di lakukan pada lembaga kursus mengemudi PRIVATE Jember yaitu Dalam pembelajarannya instruktur menerapkan strategi pembelajaran "learning with practice" atau belajar sambil praktik, jadi memang pembelajaran di PRIVATE mengacu pada kurikulum yang sudah di tetapkan, dalam pembelajarannya satu instruktur satu mobil satu peserta dan penyampaian materi langsung di berikan ketika didalam mobil dan langsung di praktikkan. 


\section{Learning Community: Jurnal Pendidikan Luar Sekolah, 3 (2), September 2o19 - 34 Alvin Septian}

Sebelum praktik instruktur memberikan materi-materi dasar terlebih dahulu di dalam mobil setelah itu peserta langsung mempraktikkan. Peserta di beri wawasan atau ilmu mengenal tools yang ada di kendaraan tersebut karena dalam mengemudi tidak harus hanya bisa mengoprasikan kendaraan saja akan tetapi perlu mengetahui fungsi, letak komponen pada mobil tersebut setelah penyampaian materi mengenai tools kendaraan peserta dapat mengetahui letak dan fungsi komponen yang ada pada kendaraan tersebut Dalam pelaksanaan pembelajaran instruktur juga memberikan himbauanhimbauan menerapkan taat berlalu lintas semisal dalam mendekati lampu merah dalam jarak kurang lebih 25 meter instruktur selalu mengingatkan agar selalu mengurangi laju kendaraan harus sabar dan taat dalam berlalu lintas. Dalam berkendara peserta selalu di beri materi Mengemudikan dan mengendalikan kendaraan bermotor secara efisien dan ramah lingkungan dengan memperhatikan keselamatan, kesehatan kerja serta keamanan dalam berkendara instruktur memberikan materi bagaimana cara benar memegang stir kemudi juga pemakaian sabuk pengaman dan juga pengoprasian kendaraan apabila berada pada kondisi menanjak.

Evaluasi pembelajaran kursus mengemudi "PRIVATE" Jember dilakukan dengan penilaian yang di laksanakan oleh setiap instruktur masing-masing. Penilaian tersebut dilakukan dengan setelah selesai porses pembelajaran, penilaian dilakukan dengan pengamatan yang dilakukan oleh instruktur kepada peserta kursus. Berdasarkan hasil wawancara yang dilakukan, Penilaian tersebut dilakukan sebagai bahan pertimbangan penilaian rapot peserta dan bahan evaluasi program pembelajaran. Berdasarkan hasil observasi dan wawancara yang dilakukan oleh peneliti evaluasi yang di lakukan setelah proses pembelajaran instruktur selalu memberikan evaluasi secara lisan maupun menggunakan media pendukung dengan tujuan memberi pemahaman kepada peserta, evaluasi pembelajaran di lakukan setelah selesai pembelajaran. Setelah materi dan praktik di berikan peserta di beri arahan dan bimbingan oleh instruktur, dalam menyalakan mobil peserta di beri wawasan atau pengetahuan mengenai start engine awal agar mesin tetap awet begitupun materi lainnya instruktur selalu evaluasi setiap selesai pembelajaran, begitu juga ketika selesai praktik berada di jalan raya instruktur juga selalu menilai bagaimana cara memegang stir kemudi yang benar, pemakaian sabuk pengaman, dan juga saat jalan ketika menghindari kendaraan berhenti di depan maupun ketika menyalip kendaraan di depan demi keselamatan berkendara untuk diri sendiri maupun orang lain.

Pembelajaran sebagai suatu sistem, langkah perencanaan pembelajaran memegang peranan penting, karena akan menentukan langkah pelaksanaan atau proses pembelajaran dan evaluasi pembelajaran. Menurut Peraturan Pemerintah No 19 Tahun 2005 Pasal 20 dalam Ahmadi dan Sofan (2011:132) ${ }^{1}$, Perencanaan proses pembelajaran meliputi silabus dan Rencana Pelaksanaan Pembelajaran (RPP) yang memuat sekurangkurangnya tujuan pembelajaran, materi pembelajaran, metode pembelajaran, sumber belajar, dan penilaian hasil belajar. Perencanaan penyusunan perangkat pembelajaran di lembaga kursus mengemudi "PRIVATE" Jember memang sudah di sesuaikan dengan standart kurikulum dari pusat kursus mengemudi "PRIVATE" Malang, berdasarkan kajian dokumen dan wawancara, kerangka dasar pembelajaran kursus mengemudi "PRIVATE" menggunakan silabus atau kurikulum sebagai alat ukur instruktur dalam melakukan perencanaan pembelajaran, Dalam proses pembelajaran peserta di beri wawasan atau ilmu mengenal tools yang ada di kendaraan tersebut karena dalam mengemudi tidak harus hanya bisa mengoprasikan kendaraan saja akan tetapi perlu mengetahui fungsi, letak komponen pada mobil tersebut setelah penyampaian materi mengenai tools kendaraan peserta dapat mengetahui letak dan fungsi komponen yang ada pada kendaraan tersebut. Dalam berkendara semua orang wajib Mentaati Undang-undang Lalu-lintas dan Angkutan Jalan yang berlaku selain demi keselamatan diri sendiri juga orang lain 


\section{Learning Community: Jurnal Pendidikan Luar Sekolah, 3 (2), September 2019 - 35}

Alvin Septian

demikian juga dalam mengikuti kursus mengemudi instruktur selalu memberikan himbauan-himbauan menerapkan taat berlalu lintas semisal dalam mendekati lampu merah dalam jarak kurang lebih 25 meter instruktur selalu mengingatkan agar selalu mengurangi laju kendaraan harus sabar dan taat dalam berlalu lintas. Dalam berkendara peserta selalu di beri materi Mengemudikan dan mengendalikan kendaraan bermotor secara efisien dan ramah lingkungan dengan memperhatikan keselamatan, kesehatan kerja serta keamanan dalam berkendara, pemakaian sabuk pengaman merupakan contoh dalam memperhatikan keselamatan berkendara, posisi tangan memegang stir kemudi juga merupakan Mengemudikan dan mengendalikan kendaraan bermotor secara efisien.

Evaluasi belajar dilakukan untuk mengetahui sejauh mana daya serap peserta pelatihan kursus mengemudi terhadap materi yang diberikan oleh instruktur, serta mengetahui peningkatan pengetahuan dan skill yang diperoleh oleh instruktur. Menurut Kirkpatrick (1998:20) dalam Widoyoko 4 bahwa evaluasi belajar dapat didefinisikan sebagai perubahan sikap, perbaikan pengetahuan dan kenaikan ketrampilan. Evaluasi pembelajaran merupakan langkah yang dilakukan untuk mengetahui seberapa efektif pembelajaran yang telah dilakukan selama kursus mengemudi berlangsung. Evaluasi pembelajaran kursus mengemudi "PRIVATE" Jember dilakukan dengan penilaian yang di laksanakan oleh setiap instruktur masing-masing.

Penilaian tersebut dilakukan dengan setelah selesai porses pembelajaran, penilaian dilakukan dengan pengamatan yang dilakukan oleh instruktur kepada peserta kursus bagaimana dalam menangkap materi-materi yang di ajarkan seperti pemahaman tentang tools kendaraan dan cara mengoprasikannya sudah cukup baik atau masih belum memahami, sikap dalam berkendara di jalan raya apakah peserta selalu mengurangi kecepatan kendaraan saat lampu rambu-rambu lalu lintas berwarna kuning dan ketika mengemudikan kendaraan apakah peserta juga selalu memakai sabuk pengaman ketika berkendara, serta mampukah peserta melaksanakan materi-materi pembelajaran sesuai dengan kurikulum kursus mengemudi "PRIVATE" yang telah ada. Hasil penelitian tersebut sesuai dengan pendapat yang dikemukakan oleh Arifin $(2009)^{2}$, yang menjelaskan bahwa tujuan evaluasi pembelajaran adalah untuk mengetahui keefektifan dan efisiensi sistem pembelajaran, baik yang menyangkut tentang tujuan, materi, metode, media, sumber belajar, lingkungan maupun system penilaian itu sendiri.

\section{SIMPULAN}

Manajemen pembelajaran memiliki peran yang sangat penting terhadap hasil belajar peserta kursus mengemudi "PRIVATE" Jember. Dalam penyusunan perangkat pembelajaran memang sudah di tentukan pada kurikulum yang ada di pusat yaitu di kota malang, dan instruktur hanya melaksanakan mengikuti yang sudah di tetapkan. Sehingga dalam penelitian ini dapat disimpulkan bahwa pelaksanaan manajemen pembelajaran lembaga kursus mengemudi "PRIVATE" dalam perencanaan memang sudah di sesuaikan dengan standart kurikulum dari pusat kursus mengemudi "PRIVATE" kota Malang, dalam pelaksanaannya instruktur memberikan materi-materi yang sudah ada pada kurikulum yang sudah di tetapkan tersebut, selanjutnya dalam evaluasi belajar dilakukan setelah selesai penyampaian materi dan praktik untuk mengetahui sejauh mana daya serap peserta kursus dalam mengangkap materi yang telah di berikan. Setelah mengikuti kursus tersebut peserta mengalami peningkatan terhadap hasil belajar kemampuan berkendara peserta pelatihan dalam ranah kognitif (pengetahuan), afektif (sikap)dan psikomotor (keterampilan).

\section{DAFTAR PUSTAKA}

Arikunto, Suharsimi dan Cepi Safrudin Abdul Jabar. 2008. Evaluasi Program Pendidikan. Jakarta: Bumi Aksara.

Ahmadi.dkk.2011.

PAIKEM GEMBROT

(Mengembangkan

Pembelajaran Aktif, Inovatif, Kreatif, Efektif, Menyenangkan, Gembira dan 
Learning Community: Jurnal Pendidikan Luar Sekolah, 3 (2), September 2019 - 36 Alvin Septian

Berbobot). Jakarta : PT. Prestasi Pustakaraya

Arifin.2009. Evaluasi Pembelajaran (PrinsipTeknik- Prosedur).Bandung: PT Remaja Rosdakarya.

Departemen Pendidikan Nasional. 2003. Undang- Undang Nomor 20 pasal 25 ayat 5 Tahun 2003,Tentang Sistem Pendidikan Nasional. Jakarta: Depdiknas.

Eko Putro Widoyoko,S.2009. Evaluasi Program Pembelajaran. Yogyakarta: Pustaka Pelajar.

Masyud, S. M. 2016. Metode Penelitian Pendidikan. Ed

Sahertian, Piet A..2000. Konsep Dasar dan Teknik Supervisi Pendidikan dalam Rangka Pengembangan Sumber Daya Manusia. Jakarta: PT. Rineka Cipta

Sudjana. 2009. Penilaian Hasil Proses Belajar Mengajar. Bandung: PT Remaja Rosdakarya.

Kementerian Pendidikan Dan Kebudayaan 2014.Standar kompetensi lulusan(SKL) kursus dan pelatihan mengemudi kendaraan bermotor kualifikasi: pengemudi profesional kendaraan pribadi level II berbasis
KKNI peraturan presiden no.8 2012.

Kementerian Pendidikan Dan

Kebudayaan 2014.Jakarta. 